cao hơn do lưới bè cần thời gian để hồi phục hoàn toàn sau điều trị.

\section{KẾT LUÂ̂N}

Nghiên cứu của chúng tôi cho thấy có mối liên quan giữa giới tính, sắc tố vùng, nhãn áp trước điều trị với thành công điều trị. Không có mối liên quan có ý nghĩa thống kê giữa tuổi, thời gian mắc bệnh, số thuốc tra hạ nhãn áp trước điều trị, giai đoạn bệnh, năng lượng laser đến thành công của điều trị.

\section{TÀI LIÊU THAM KHẢO}

1. Anderson RR, Parish JA. Selective photothermolysis: Precise microsurgery by selective absorption of pulsed radiation. Science 1983 Apr;220(4596):524-527.

2. Ayala $\mathbf{M}$, Chen $\mathbf{E}$. Predictive factors of success in selective laser trabeculoplasty (SLT) treatment. Clin Ophthalmol. 2011;5:573-576. doi:10.2147/ OPTH.S19873

3. Gracner T, Naji M, Hudovernik M, Gracner B, Pahor D. [Predictive factors of successful selective laser trabeculoplasty in open-angle glaucoma]. Klin Monbl Augenheilkd. 2007;224(12):922-926. doi:10.1055/s-2007-963744

4. Hodge WG, Damji KF, Rock W, Buhrmann R,
Bovell AM, Pan Y. Baseline IOP predicts selective laser trabeculoplasty success at 1 year posttreatment: results from a randomised clinical trial. British Journal of Ophthalmology. 2005;89 (9):1157-1160. doi:10.1136/bjo.2004.062414

5. Mao AJ, Pan XJ, McIlraith $I$, Strasfeld $M$, Colev G, Hutnik C. Development of a prediction rule to estimate the probability of acceptable intraocular pressure reduction after selective laser trabeculoplasty in open-angle glaucoma and ocular hypertension. J Glaucoma 2008 Sep;17(6):449-454.

6. Hirabayashi M, Ponnusamy V, An J. Predictive Factors for Outcomes of Selective Laser Trabeculoplasty. Sci Rep. 2020;10. doi:10.1038/s41598-020-66473-0

7. Pillunat KR, Spoerl E, Elfes G, Pillunat LE. Preoperative intraocular pressure as a predictor of selective laser trabeculoplasty efficacy. Acta Ophthalmologica. doi:10.1111/aos.13094

8. Lee JWY, Liu CCL, Chan JCH, Lai JSM. Predictors of success in selective laser trabeculoplasty for chinese open-angle glaucoma. J Glaucoma. 2014; 23(5):321-325. doi: 10.1097/ IJG.0000000000000049

9. Kuley B, Zheng CX, Zhang $Q$ (Ed), et al, Predictors of Success in Selective Laser Trabeculoplasty. Ophthalmology Glaucoma. 2020;3 (2):97-102. doi:10.1016/j.ogla.2019.11.010

\title{
ĐÁNH GIÁ KẾT QUẢ PHẪU THUÂT VÁ THỦNG VÁCH LIÊN THẤT SAU NHỒI MÁU CO' TIM
}

\section{TÓM TẮT}

Mở đâu: Thủng vách liên thất là môt biến chứng nặng và ít gặp của nhồi máu cơ tim cấp. Bệnh nhân không điều trị phẫu thuật có tỉ lệ tử vong cao. Có nhiều loai phẫu thuật điều trị bệnh lý này, trong đó có vá lỗ thủng vách liển thất bẳng kĩ thuật hai miếng vá qua đường mở thất phải. Đề tài nhằm muc tiêu đánh giá kết quả của phẩu thuật điều trị thủng vách liên thất sau nhồi máu cơ tim bằng phương pháp hai miếng vá qua đường mở thất phải. Đối tượng Phương pháp nghiên cứu: Hồi cứu, mô tả loạt ca được phẫu thuật vá lỗ thủng vách liên thất bằng phương pháp hai miếng vá qua đường mở thất phải tại Bệnh viện Chợ Rẫy từ tháng 01/2014 đến tháng $01 / 2020$. Kết quả: Từ tháng $01 / 2014$ đến tháng 01/2020, chúng tôi sử dụng phương pháp vá lỗ thông liên thất bằng hai miếng vá cho 36 bệnh nhân. Tuổi trung bình của các bệnh nhân là $67,2 \pm 11,4$ tuổi. Có 28 bệnh nhân là nam, chiếm 77,8\%. Thời gian kẹp

*Trung tâm Tim - Mạch bệnh viện Chợ Rẫy.

Chịu trách nhiệm chính: Trần Quyết Tiến

Email: tienchoray@yahoo.com

Ngày nhận bài: 25.01.2021

Ngày phản biên khoa họ: 19.3.2021

Ngày duyệt bài: 29.3.2021
Trần Quyết Tiến*

động mạch chủ trung bình 97,4 phút. Thời gian chạy tuần hoàn ngoài cơ thể trung bình 146,2 phút. Tỉ lệ tử vong sớm là $22,2 \% ; 3$ trường hợp tai biến mạch máu não, 4 trường hợp chảy máu cần mổ lại, 5 trường hợp suy thận cần chạy thận nhân tạo. 1 trường hợp tử vong trung hạn vì nhồi máu cơ tim tái phát. Kết luận: Phẫu thuật vá thủng vách liên thất sau nhồi máu cơ tim bằng kĩ thuật hai miếng vá an toàn, hiệu quả và có kết quả trung han tốt. Kî thuật có ưu điểm là đơn giản, ít khả năng tái phát thông liên thất và có thể áp dụng được cho cả thủng vách liên thất phía trước và phía sau.

\section{SUMMARY \\ THE SURGICAL TREATMENT RESAULT OF VENTRICULAR SEPTAL DEFECT DUE TO MYOCARDIAL INFARCTION}

Introduction: Ventricular septal perforation is a serious and uncommon complication of acute myocardial infarction. Patients without surgical treatment have a high mortality rate. There are many types of surgery to treat this disease, including twopatch technique through the right ventriculotomy. The research aims to evaluate the results of surgery for the treatment of ventricular septal perforation after myocardial infarction by the two-patch technique. Methods: This is a retrospective case series of 
repairing ventricular septal perforation by the twopatch technique through the right ventriculotomy at Cho Ray Hospital from January 2014 to January 2020. Results: From January 2014 to January 2020, we used the two-patch method to repair the ventricular septum perforation for 36 patients. The mean age of the patients was $67.2 \pm 11.4$ years. There are 28 male patients (77.8\%). Mean aortic clamping time was 97.4 minutes. Mean cardiopulmonary bypass time was 146.2 minutes. Early mortality rate is $22.2 \%$; there were 3 cases of postoperative stroke, 4 cases of bleeding requiring re-operation, 5 cases of renal failure requiring hemodialysis. For the mid-term result, there was death from recurrent myocardial infarction. Conclusions: Ventricular septal perforation surgery after myocardial infarction with the two-patch technique is safe, effective and has good mid-term results. The technique has the advantage of simplicity, less likely to have recurrent of the ventricular septum defect and can be applied to both anterior and posterior ventricular septal perforation.

\section{I. Đă̆T VẤN ĐỀ}

Thủng vách liên thất là một biến chứng nặng và ít gặp của nhồi máu cơ tim cấp. Bệnh nhân không điều trị phẫu thuật có tỉ lệ tử vong $24 \%$ trong ngày đầu tiên và lển đến $80 \%$ trong tháng đầu tiên. Điều trị phẫu thuật giúp cải thiện tiên lượng sống còn của bệnh nhân, tuy vậy, theo báo cáo của hội phẫu thuật lồng ngực Hoa Kì (STS), tỉ lệ tử vong sớm sau phẫu thuật vẫn còn $54,1 \%$ khi thực hiện phấu thuật trong vòng 7 ngày sau nhồi máu cơ tim cấp [1].

Latham ghi nhận trường hợp thủng vách liên thất đầu tiên do biến chứng nhồi máu cơ tim cấp trên tử thiết vào năm 1847 [7]. 110 năm sau (1957), Denton A. Cooley lần đâu tiên thực hiện phẫu thuật vá thủng vách liên thất sau nhồi máu cơ tim [4]. Bệnh nhân nhập viện vì tắc động mạch vành phải, thủng vách liên thất xuất hiện vào ngày thứ 5 sau nhồi máu và phẫu thuật được thực hiện 11 tuần sau biến chứng. Cooley tiếp cận lỗ thông liên thất qua đường mở giữa thất phải và cắt cơ nhú sau để bộc lộ rõ ràng lỗ thông liên thất. Sau phẫu thuật, tiếng thổi của thông liên thất không còn và bệnh nhân tam thời phục hồi. Tuy vậy, suy tim vẫn tiếp tục diễn tiến ngày càng năng hơn và bệnh nhân tử vong ở ngày hậu phẩu thứ 45 . Tử thiết ghi nhận miếng vá thông liên thất bung 1 phần và tạo ra thông liên thất tái phát. Báo cáo cưa Cooley đã đem lại hy vọng có thể điều trị phẫu thuật cho bệnh lý này. Năm 2012, Asai và cộng sự đề xuất cách vá lỗ thủng vách liên thất bằng kĩ thuật hai miếng vá qua đường mở thất phải, đã đạt được kết quả ngắn hạn và trung hạn khá tốt so với các kĩ thuật trước đây [3], [6]

Chúng tôi báo cáo kết quả ngắn hạn và kết quả trung hạn của phẫu thuật điều trị thủng vách liên thất sau nhồi máu cơ tim bằng phương pháp hai miếng vá qua đường mở thất phải tại Bệnh viện Chợ Rẫy.

\section{II. ĐỐI TƯỢNG VÀ PHƯƠNG PHÁP NGHIÊN CỨU Phương pháp nghiên cứu: Mô tả loạt ca,} hồi cứu.

Trích lục dữ liệu hồ sơ bệnh án và thu thập số liệu tiến cứu tại Khoa Hồi sức - Phẫu Thuật Tim, Bệnh viện Chợ Rẫy của các bệnh nhân được phẫu thuật vá thủng vách liên thất sau nhồi máu cơ tim cấp thời gian từ tháng 01/2014 đến tháng 01/2020.

\section{Tiêu chuẩn chọn bệnh:}

+ Bệnh nhân nhồi máu cơ tim cấp có thủng vách liên thất mới

+ Được phẫu thuật đóng vách liên thất hai lớp qua đường mở thất phải.

\section{Tiêu chuân loại trừ:}

+ Có bệnh tim khác cần can thiệp: Van ĐMC, van hai lá, bệnh tim bẩm sinh..

+ Bệnh nhân vá lỗ thủng vách liên thất bằng kĩ thuật khác.

Theo dõi bệnh nhân: Bệnh nhân được tái khám hàng tháng tại phòng khám khoa Hồi sức Phẫu thuật Tim - Bệnh viện Chợ Rẫy.

Siêu ầm tim được thực hiện tại thời điểm trước xuất viện, 1 tuần, 1 tháng, 3 tháng, 6 tháng, 1 năm và mỗi 6 tháng.

Trường hợp bệnh nhân không tái khám: Gọi điện thoại mời bệnh nhân tái khám và siêu âm tim.

Khi không liên hệ được: Mất mẫu

Xử lí số liệu: Số liệu thống kê được xử lý bằng phần mềm Excel và $R$. Các biến số liên tục được mô tả bằng số trung bình \pm độ lệch chuẩn. Các biến số liên tục không tuân theo phân phối chuẩn được mô tả bằng số trung vị và khoảng tứ phân vị. Các biến số phân loại được mô tả bằng tần suất và tỉ lệ phần trăm.

Kĩ thuật phấu thuật. Bệnh nhân nằm ngửa, kê gối dưới vai. Mở ngực đường giữa xương ức. Mở màng tim, bộc lộ tim và các mạch máu lớn. Thiết lập tuần hoàn ngoài cơ thể với ống thông động mạch chủ và ống thông tĩnh mạch chủ trên, tĩnh mạch chủ dưới. Trước khi khởi chạy tuần hoàn ngoài cơ thể, cần sờ phía trước hoặc sau thất phải để cảm nhận âm thổi của lỗ thông liên thất. Bảo vệ cơ tim bằng cách bơm dung dịch liệt tim thuận dòng qua gốc động mạch chủ.

Đối với thông liên thất phần trước, lỗ thông thường nằm ở phía xa của động mạch liên thất trước (LAD). Mở thất phải song song với $L A D$, cách LAD 1 đến $1,5 \mathrm{~cm}$ (Hình 1 ). 


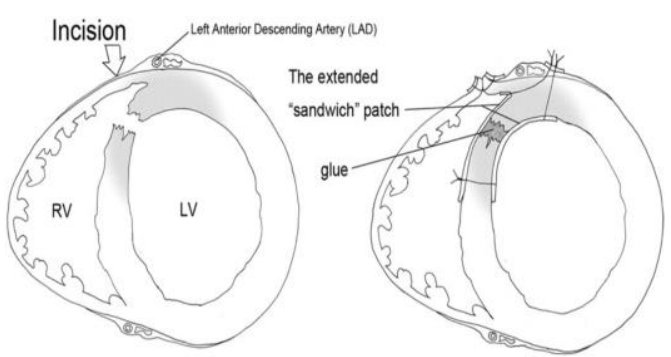

Hình 1. Đường mở thất phải ở phía trước và cách đóng thông liên thất trong kĩ thuật 2 miêng vá; Nguồn: Asai (2012) [3]

Các dải cơ bè được cắt một phần để bộc lộ rõ lỗ thông. Mô cơ tim hoai tử quanh lỗ thông cũng được cắt bỏ vừa đủ để đảm bảo vùng khâu được chắc chắn. Hai miếng vá được cắt sao cho bờ của miếng vá lớn hơn bờ lỗ thông khoảng $1,5 \mathrm{~cm}$. Khâu miếng vá đầu tiên vào thành của vách liên thất hoặc thành tự do thất trái bằng chỉ Polypropylen 3-0, khoảng cách giữa mỗi mũi chỉ là $1 \mathrm{~cm}$ (Hình 2). Các mũi chỉ trong thất phải được khâu qua miếng vá thứ 2.Các mũi chỉ ra ngoài thành tự do thất trái được khâu qua miếng đệm Teflon lớn dọc theo đường mở thất phải. Sau đó keo sinh học được bơm vào giữa 2 miếng đệm để tăng cường độ chắc chắn. Đường mở thất phải được đóng lại bằng chỉ Polypropylen với 2 miếng đệm Teflon dày ở hai bên để tránh chảy máu sau đó.

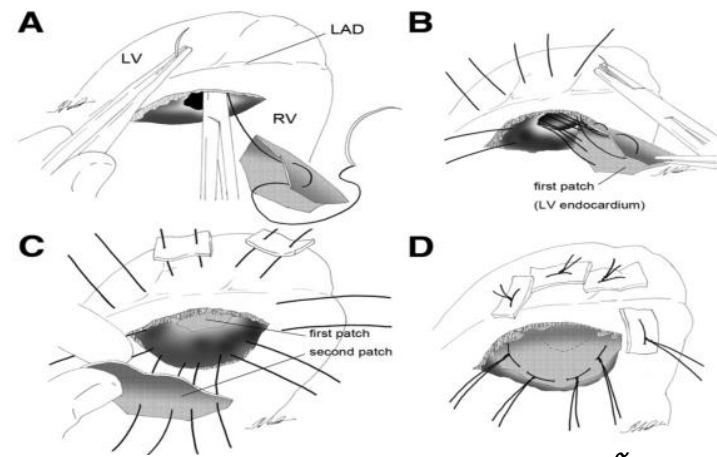

Hình 2. Ki thuật đóng 2 miếng vá cho lỗ thông liên thất phía trước; Nguồn: Asai (2012) [3]

Đối với lỗ thông liên thất phía sau, nguyên tắc đóng lỗ thông tương tự như đóng lố thông liên thất phía trước

\section{KẾT QUẢ NGHIÊN CỨU}

Từ tháng 01/2014 đến tháng 01/2020, chúng tôi sử dụng phương pháp vá lồ thông liên thất bằng hai miếng vá cho 36 bệnh nhân. Tuổi trung bình của các bệnh nhân là $67,2 \pm 11,4$ tuổi. Có 28 bệnh nhân là nam, chiếm 77,8\%. Lý do nhập viện chính là đau ngực, sau đó là khó thở, có 1 bệnh nhân nhập viện vì ngất. Thông số trong mổ được thống kê ở bảng 1.

Bảng 1. Thông số phẫu thuật vá thủng vách liên thât

\begin{tabular}{|c|c|}
\hline Biến số & Số lượng (n, \%) \\
\hline Thông liên thất phía trước & $22(61,1)$ \\
\hline $\begin{array}{c}\text { Phấu thuật bắc cầu mạch } \\
\text { vành đi kèm }\end{array}$ & $30(83,3)$ \\
\hline $\begin{array}{c}\text { Số lượng cầu nối mạch vành } \\
\text { trung bình }\end{array}$ & $1,7 \pm 0,9$ \\
\hline $\begin{array}{c}\text { Thời gian kẹp động mạch } \\
\text { chù trung bình (phút) }\end{array}$ & $97,4 \pm 36,5$ \\
\hline $\begin{array}{c}\text { Thời gian tuần hoàn ngoài } \\
\text { cơ thể trung bình (phút) }\end{array}$ & $146,2 \pm 42,6$ \\
\hline
\end{tabular}

Kết quả phẫu thuật sớm được liệt kê trong bảng 2.

Bảng 2. Kêt quả phẫu thuật sớm

\begin{tabular}{|c|c|}
\hline Biến số & $\begin{array}{c}\text { Số lượng } \\
(\mathbf{n}, \mathbf{\%})\end{array}$ \\
\hline Tử vong sớm (trong vòng 30 ngày) & $8(22,2 \%)$ \\
\hline Tai biến mạch máu não không hồi phục & $3(8,3)$ \\
\hline Thở máy kéo dài & $34(94,4)$ \\
\hline Suy thận cần chạy thận nhân tạo & $5(13,9)$ \\
\hline Chày maáu cần phấu thuật lại & $4(11,1)$ \\
\hline Nhiếm trùng xương ức & $1(2,8)$ \\
\hline
\end{tabular}

\section{Hình 3: Vá lố thông liên thất qua đường mở thất phải tại Bêenh viện Chơ Rẫy}

Chúng tôi có 8 trường hợp tử vong sớm, chiếm $22,2 \%$. Trong đó có 7 trường hợp nhồi máu cơ tim cấp có thủng vách liên thất sớm, gây ảnh hưởng huyết động và phải đặt bóng đối xung động mạch chủ, mổ tối khẩn. Vì vậy, tỉ lệ tử vong của nhóm này rất cao. Có 3 bệnh nhân bị tai biến mạch máu não không hồi phục, trong đó có 2 trường hợp nhồi máu não, 1 trường hợp xuất huyết não. Có 2 bệnh nhân tai biến mạch máu não tử vong sớm do thở máy kéo dài, viêm phổi. Có 5 trường hợp suy thận sớm sau phẫu thuật cần phải chạy thận nhân tạo, trong đó có 3 bệnh nhân phục hồi hoàn toàn, 2 bệnh nhân tử vong. 4 trường hợp cần phẫu thuật lại cầm máu, 2 trường hợp chảy máu từ đường đóng thất phải, 1 trường hợp chảy máu giường động mạch ngực trong và 1 trường hợp chảy máu từ xưởng ức. Chỉ có 1 trường hợp nhiếm trùng xương ức 
được ghi nhận trong nhóm bệnh nhân của chúng tôi, chiếm tỉ lệ 2,8\%.

Thời gian theo dõi trung bình là $14,2 \pm 6,1$ tháng. Có một trường hợp tử vong trong giai đoạn theo dõi do nhồi máu cơ tim cấp tái phát. Khồng có trường hợp nào phải phẫu thuật lại. Không ghi nhận thông liên thất tồn lưu trên siêu âm tim trong quá trình theo dõi.

\section{BÀN LUÂN}

Tác giả David và cộng sự giới thiệu một phương pháp phẫu thuật điều trị thủng vách liền thất qua đường mở thất trái. Các tác giả sử dụng một miếng màng ngoài tim lớn để loại bỏ lố thủng trên vách liên thất và chỗ mở thất trái bằng mũi khâu liên tục [5]. Tuy có kết quả tương đối khả quan, nhưng phương pháp này tồn tại hai nhược điểm. Nhược điểm đâu tiên là đường khâu liên tục phải đi qua một diện tích lớn, vì vậy, chỉ cần một điểm tồn lưu có thể làm bung một đoạn lớn đường khâu này và gây ra tái phát thổng liển thất dòng lớn, làm suy tim và tử vong sau mồ. Phẫu thuật viên có thể gặp khó khăn ở đường khâu phía sau vì cơ nhú sau bên và van hai lá có thể cản trở. Nhược điểm thứ hai là diện tích của miếng vá màng tim quá lớn (che lỗ thông và che đường mở thất trái) có thể làm ảnh hưởng chức năng co bóp thất trái [3]. Năm 2012, tác giả Asai và cộng sự giới thiệu kĩ thuật đóng lỗ thông liên thất bằng hai miếng vá, kĩ thuật này đã loại bỏ được những điểm yếu này [3].

Kĩ thuật vá thông liên thất bằng hai miếng vá có nhiêu ưu điểm, đường mở thất phải song song với các động mạch quan trong ít gây ảnh hưởng tưới máu thất phải và không làm tổn thương thành thất trái. Giải phẫu của thất phải cho phép tiếp cận lỗ thông liên thất tốt hơn, giúp giảm thiểu nguy cơ tổn thương bộ máy dưới van hai lá. Kĩ thuật 2 miếng vá dạng "sandwich", có keo sinh học bơm và làm phồng thành hình thấu kính 2 mặt lồi giúp giảm thiếu những rối loạn huyết động có thể có khi tim co bóp [2]

Miếng vá lỗ thông được khâu chắc chắn bằng các sợi chỉ có đệm xuyên qua toàn bộ chiều dày của vách liên thất, làm giảm thiểu nguy cơ thông liên thất tồn lưu hoặc thông liên thất tái phát. Diện tích miếng vá làm theo kĩ thuật này nhỏ hơn nhiều so với kĩ thuật được David đề nghị trước đây.

Tác giả Hosoba và cộng sự báo cáo kết quả ngắn hạn và trung hạn của kĩ thuật vá lỗ thông liên thất bằng hai miểng vá trên 15 bệnh nhân ở một trung tâm, 94\% bệnh nhân được điều trị trong vòng một tuần sau khi có biến chứng, $67 \%$ có thông liên thất sau. Tỉ lệ tử vong là $20 \%$. Không có thông liên thất tái phát trong giai đoạn hậu phẫu sớm và giai đoạn theo dõi sau đó [6].

Cách tiếp cận này cũ̃ng giúp bảo vệ tối đa phần cơ tim còn sống còn, Chức năng thất phải sau mổ đo bằng tỉ lệ thay đổi diện tích thất phải (RVFAC) còn trong giá trị bình thường [2]. Tác giả Asai báo cáo thêm 10 trường hợp tiếp tục sau 15 bệnh nhân của Hosoba, trong đó có 9 trường hợp thủng vách liên thất trước và 1 trường hợp thủng vách liên thất sau, tỉ lệ tử vong nội viện tích lũy là $12 \%(3 / 25)$. Các tác giả kết luận phương pháp vá thông liên thất này an toàn, đơn giản, có thể được sử dụng cho cả thủng vách liên thất trước và sau và làm giảm nguy cơ tái phát, mổ lại [2]

\section{KẾT LUÂNN}

Phẫu thuật vá thủng vách liên thất sau nhồi máu cơ tim bằng kĩ thuật hai miếng vá an toàn, hiệu quả và có kết quả trung hạn tốt. Kĩ thuật có ưu điểm là đơn giản, ít khả năng tái phát thông liên thất và có thể áp dụng được cho cả thủng vách liên thất phía trước và phía sau.

\section{TÀl LIỆ THAM KHẢO}

1. Arnaoutakis G. J., Zhao Y., George T. J., Sciortino C. M., McCarthy P. M., and Conte J. V. (2012), "Surgical repair of ventricular septal defect after myocardial infarction: outcomes from the Society of Thoracic Surgeons National Database", Ann Thorac Surg. 94(2): pp. 436-43; discussion 443-4.

2. Asai T. (2016), "Postinfarction ventricular septal rupture: can we improve clinical outcome of surgical repair?", Gen Thorac Cardiovasc Surg. 64(3): pp. 121-30.

3. Asai T., Hosoba S., Suzuki T., and Kinoshita T. (2012), "Postinfarction ventricular septal defect: right ventricular approach-the extended "sandwich" patch", Semin Thorac Cardiovasc Surg. 24(1): pp. 59-62.

4. Cooley D. A., Belmonte B. A., Zeis L. B., and Schnur S. (1957), "Surgical repair of ruptured interventricular septum following acute myocardial infarction", Surgery. 41(6): pp. 930-7.

5. David T. E., Feindel C. M., and Ropchan G. V. (1987), "Reconstruction of the left ventricle with autologous pericardium", J Thorac Cardiovasc Surg. 94(5): pp. 710-4.

6. Hosoba S., Asai T., Suzuki T., Nota H., Kuroyanagi S., Kinoshita T., Takashima N., and Hayakawa M. (2013), "Mid-term results for the use of the extended sandwich patch technique through right ventriculotomy for postinfarction ventricular septal defects", Eur J Cardiothorac Surg. 43(5): pp. e116-20.

7. PM L. (1845), "Lectures on subjects connected with clinical medicine comprising diseases of the heart", London: Longman Rees. 2: pp. 168-74. 